\title{
The Impact of Organisational Restructuring on Organisation Climate and Employee Attitudes
}

\section{H E Brand and $\mathbf{J}$ Wilson}

Department of Human Resources Management, University of Pretoria

\section{ABSTRACT}

This study investigated the impact of an organisational restructuring intervention on the climate of an organisation and the attitudes of its employees. An organisation climate and employee attitude questionnaire were used as measuring instruments. A convenience sample was used, comprising all personnel of the specific organisation. Results show that the restructuring did in fact influence the organisation climate and affected employee attitudes. Recommendations based on the results of and experiences gained from the study, are that effective communication should be seen as having a direct influence on successful organisation restructuring and that an effective performance management system is essential in providing employees with opportunities to measure own performance against organisation performance standards during a period of restructuring and change.

JEL M 12

\section{BACKGROUND}

Business process re-engineering has become an important instrument of organisation development, with the objective of making organisations more competitive by streamlining work processes, re-defining jobs within the organisation and redesigning the overall organisational structure (Donaldson, 1994). These strategies and changes have a profound impact on organisation climate and employee attitudes (Kochan \& Useem, 1992). Organisational climate, according to Veldsman (1995), refers to the psychological structures of organisations and their sub-units, and can also be described as the personality or character of the organisation's internal environment. The internal environment is influenced by various forces and in turn influences aspects such as employee achievement, behaviour, attitudes and job satisfaction (Veldsman, 1995). Organisation climate is determined by both external and internal factors, for example economic conditions, leadership styles, and organisation policies and procedures (Robbins, 1996). While the characteristics of organisation climate may 
vary from one organisation to another, there are also common elements of climate across different organisations (Moran \& Volkwein, 1992). Milton (1981) draws the following conclusions from extensive investigations into organisation climate :

- Organisations may have multiple climates which can be affected differently by various organisational interventions, for example organisational restructuring.

- Climate is often perceived differently by top, middle and lower levels of management, indicating that changes in climate can also be differently perceived and experienced by these management levels.

- Evidence suggests that organisations have climates that differ from one another, meaning that climate changes will impact differently on the various organisations.

- Organisation studies have clearly indicated that climate variables influence the predictability of such aspects as employee performance, job satisfaction and motivation. Changes in climate variables can thus also affect these aspects.

Attitudes are the result of the feelings and beliefs that one has about one's self, as well as about other people and situations (Lamberton \& Minor, 1995). Attitudes also directly influence one's behaviour. According to Kochan \& Useem (1992), it is almost impossible to implement organisational change or restructuring without affecting the prevailing employee attitudes within the organisation.

Various theories have been postulated trying to explain the process of change which occurs in employees' attitudes when some form of organisational change is implemented, for example, the group dynamic approach and the Yale attitude change approach (Zimbardo \& Leippe, 1991). Although present attitudes relate to past experience, the problem in organisation management is the future tense of attitudes. The individual, the people surrounding the individual and the environment are in a constant state of change. This means that attitudes supporting the individual's personal development in the present need to be changed, if they are to perform the same or a different function in the future. According to Kochan \& Useem (1992), attitude change can be classified in two ways, namely:

The congruent change: This change is classified as a change in intensity, but not in the direction of an existing attitude. If employees, for example, have a negative attitude towards their job, this attitude can be intensified by a bad experience or a bad working environment. The result is that the employee can form an even more unfavourable attitude towards work. 
The incongnuent change: This refers to changes in direction of the individual's attitude. It simply implies, for example, that an employee's unfavourable or negative attitude towards work can be changed to a favourable way of thinking.

It is widely accepted that an intervention such as organisation restructuring or change, can significantly contribute towards attitude changes among employees, which in turn affects employee loyalty, productivity and motivation either positively or negatively, depending on the nature and direction of the attitude changes (Donaldson, 1994; Heymans, 1997; Robbins, 1996).

\section{THIS STUDY}

Within the framework of the above-mentioned corporate properties, the organisation in which this study was done in fact embarked on a process of extensive organisation restructuring, and identified, among others, the need to determine the impact of the restructuring process on the organisation's climate and its employees' attitudes, which are the joint objective of this study. The study aimed at determining whether climate and employee attitude were in fact influenced by the restructuring process, as well as the direction of change.

The following two pairs of hypotheses were formulated and tested:

Ho: The organisation climate of the organisation involved is affected by the restructuring process.

$\mathrm{H}_{1}$ : The organisation climate of the organisation involved is not affected by the restructuring process.

Ho: Employee attitudes are affected by the organisation restructuring process.

$\mathrm{H}_{1}$ : Employee attitudes are not affected by the organisation restructuring process.

\section{Research Method}

The research method followed in this study, is discussed under the headings of research strategy, research group, sample, response rate and data analysis.

\section{Research Strategy}

The survey method in this study, to determine the impact of organisation restructuring on organisation climate and employee attitudes, was to use two questionnaires as measuring instruments. The organisational climate questionnaire was applied to all the employees of the specific organisation before the onset of the restructuring process, and again six months after the completion of the 
process. The attitude questionnaire was applied to all employees six months after completion of the restructuring process. The questionnaires were distributed together with an information brochure, indicating the motivation for and characteristics of the study, as well as the relevant instructions. It was also clearly stated that the study was conducted with the approval and support of the organisation's top management.

The following are the particulars of the two questionnaires:

Litwin and Stinger's Organisational Climate Survey questionnaire: This 40item questionnaire, grouped into nine elements of organisational climate, was used to measure the employees' perception of the organisation climate. This instrument was also adapted in 1972 for use in South Africa. This version of the questionnaire is commonly used in South Africa and in previous studies obtained a Cronbach's Alpha of between 0.80 and 0.83 (Heymans, 1997; Otterman,1991; Veldsman, 1995). The nine elements evaluated in this questionnaire are the following:

$\begin{array}{ll}\text { - } & \text { Structure } \\ \text { - } & \text { Responsibility } \\ \text { - } & \text { Warmth } \\ \text { - } & \text { Support } \\ \text { - } & \text { Standards } \\ \text { - } & \text { Conflict } \\ \text { - } & \text { Identity } \\ \text { - } & \text { Recognition } \\ \text { - } & \text { Risk }\end{array}$

The Likert-scale is used for the evaluation of the items in the following manner:

1 - agree strongly

2 - agree slightly

3 - unsure

4 - disagree slightly

5 - disagree strongly

Employee attitude questionnaire: A 16-item questionnaire was used to determine the employees' general "feel" or perceptions of the organisational restructuring process that was implemented. The 16 items included here in the form of statements to which employees expressed their opinions, are the following:

- Changes that have taken place had no influence on the organisation.

- I do not react to the changes that have taken place. 
- The changes do not influence me directly.

- Management did not discuss any changes with me.

- I feel that the changes pose a threat to my career within the organisation.

- I feel that the changes which already have taken place were unnecessary.

- If I would receive an employment offer from another organisation with the same remuneration package, I will definitely consider resigning.

- During the last couple of months, I have experienced more conflict with management/colleagues than usual.

- I make it a point to know what changes are taking place and how this will affect me personally.

- The impact of these changes on my career have been discussed with my manager.

- I feel that the changing environment brings about new challenges and opportunities for me personally.

- I would like to rapidly develop myself to be able to meet the set requirements of change.

- I feel positive that these changes provide an opportunity for greater success of the organisation.

- The changes that have taken place have influenced the cooperation and team spirit in the organisation.

- I am fully informed of the newly defined action plans of the organisation.

- In changing times, I see myself as a supporter of the process.

The Likert-scale is also used for the evaluation of the items in the same format as with the Organisation Climate Survey Questionnaire (from 1: agree strongly to 5: disagree strongly).

\section{Research Group}

The research group consists of all the employees of a national organisation operating in the property development market, numbering a total of 80 people.

\section{Sample}

A convenience sample was utilised, including all employees of the organisation.

\section{Response Rate}

A response rate of $100 \%$ was obtained for the sample. 


\section{Data Analysis}

The above-mentioned questionnaires were completed by the respondents, after which the data were captured in order to obtain statistical information for analysis and interpretation. The data derived from these questionnaires were analysed by means of the descriptive statistics of the SPSS-Windows computer programme. The arithmetic means and standard deviations of the various elements and items were used to determine any significant differences in the results of the prerestructuring and post-restructuring testing.

\section{Results of the Study}

Organisation climate evaluation: The results of the evaluated elements of organisation climate, prior to and after the organisation restructuring intervention, are shown in Table 1.

\section{Table 1 Organisation climate evaluation}

\begin{tabular}{|c|c|c|c|}
\hline Element & Item & $\begin{array}{c}\text { Pre-restruc. } \\
\text { (mean) }\end{array}$ & $\begin{array}{l}\text { Post-restruc. } \\
\text { (mean) }\end{array}$ \\
\hline \multirow[t]{5}{*}{ Structure } & 1 & 3,250 & 2,00 \\
\hline & 9 & 2,533 & 2,533 \\
\hline & 18 & 2,562 & 1,937 \\
\hline & 27 & 3,250 & 3,500 \\
\hline & 40 & 3,000 & 1,937 \\
\hline Arithmetic mean & & 2,919 & 2,381 \\
\hline \multirow[t]{4}{*}{ Responsibility } & 2 & 2,625 & 2,312 \\
\hline & 10 & 3,067 & 2,200 \\
\hline & 19 & 2,937 & 2,267 \\
\hline & 28 & 3,062 & 2,187 \\
\hline Arithmetic mean & & 2,923 & 2,241 \\
\hline \multirow[t]{4}{*}{ Warmth } & 4 & 3,125 & 2,062 \\
\hline & 23 & 3,937 & 2,625 \\
\hline & 30 & 2,250 & 2,187 \\
\hline & 35 & 3,000 & 1,812 \\
\hline Arithmetic mean & & 3,078 & 2,687 \\
\hline \multirow[t]{6}{*}{ Support } & 5 & 2,667 & 2,200 \\
\hline & 11 & 3,250 & 2,125 \\
\hline & 14 & 3,625 & 2,875 \\
\hline & 31 & 2,750 & 2,067 \\
\hline & 36 & 2,750 & 1,750 \\
\hline & 38 & 3,000 & 3,437 \\
\hline
\end{tabular}


Table 1 continued

\begin{tabular}{|c|c|c|c|}
\hline Element & Item & $\begin{array}{c}\text { Pre-restruc. } \\
\text { (mean) }\end{array}$ & $\begin{array}{c}\text { Post-restruc. } \\
\text { (mean) }\end{array}$ \\
\hline Arithmetic mean & & 3,007 & 2,409 \\
\hline \multirow[t]{6}{*}{$\begin{array}{l}\text { Standards } \\
\end{array}$} & 6 & 3,467 & 2,067 \\
\hline & 15 & 3,533 & 2,437 \\
\hline & 22 & 2,875 & 2,500 \\
\hline & 24 & 3,000 & 2,375 \\
\hline & 37 & 2,625 & 2,812 \\
\hline & 39 & 2,875 & 2,125 \\
\hline Arithmetic mean & & 3,063 & 2,386 \\
\hline \multirow[t]{4}{*}{ Conflict } & 7 & 2,312 & 2,875 \\
\hline & 16 & 2,937 & 3,437 \\
\hline & 25 & 3,500 & 2,187 \\
\hline & 32 & 3,062 & 2,062 \\
\hline Arithmetic mean & & 2,953 & 2,640 \\
\hline \multirow[t]{3}{*}{ Identity } & 8 & 2,875 & 1,812 \\
\hline & 17 & 2,812 & 1,812 \\
\hline & 26 & 3,250 & 2,187 \\
\hline Arithmetic mean & & 2,979 & 1,937 \\
\hline \multirow[t]{5}{*}{ Recognition } & 3 & 3,125 & 2,187 \\
\hline & 12 & 3,125 & 2,000 \\
\hline & 20 & 3,000 & 2,267 \\
\hline & 21 & 3,000 & 2,067 \\
\hline & 33 & 3,250 & 2,250 \\
\hline Arithmetic mean & & 3,100 & 2,153 \\
\hline \multirow[t]{3}{*}{ Risk } & 13 & 3,500 & 2,125 \\
\hline & 29 & 2,812 & 1,750 \\
\hline & 34 & 2,562 & 2,687 \\
\hline Arithmetic mean & & 2,958 & 2,817 \\
\hline
\end{tabular}

According to Table 1, all nine elements have seemingly been affected by the organisation restructuring process. In the employees' perceptions, the direction of change was positive in all nine cases (according to the Likert-scale used for each item). In order of priority (most affected to least affected), determined by the width of the mean differences, the elements appear in the following order:

Identity

Recognition

Responsibility

Standards

Support 
Structure

Warmth

Conflict

Risk

Thus the null hypothesis relating to this part of the study is supported and the alternative hypothesis rejected.

Employee attitude evaluation: The results obtained from the attitude study (16 attitude variables) are shown in Figure 1.

Figure 1 Employee attitude evaluation : Arithmetic means (questions 1-16)

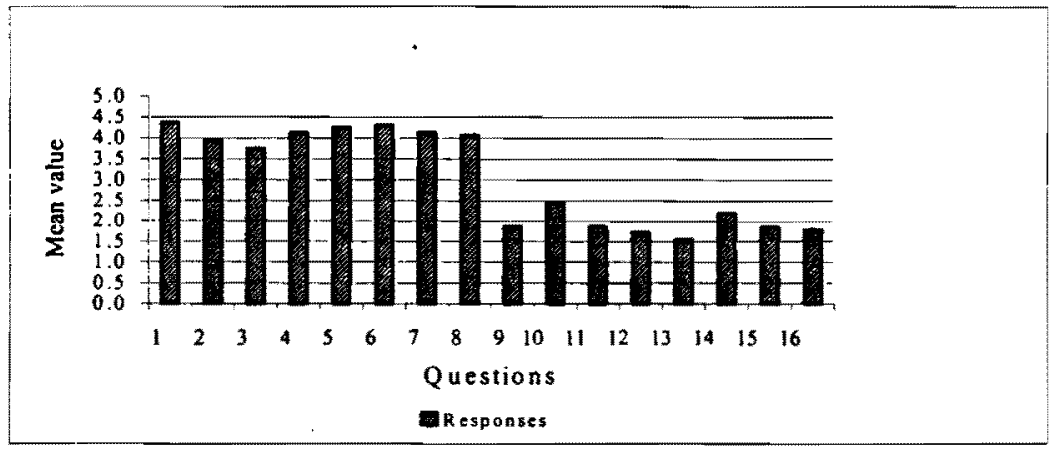

Figure I shows that the employees of the organisation seemingly disagreed with the statements related to items 1 to 8 in the attitude questionnaire, indicating that the organisation restructuring process and its accompanying changes affected the employees' respective attitudes in a positive manner (according to the Likert-scale used with each item). Figure 1 also shows that the employees seemingly agreed with the statements related to items 9 to 16 of the questionnaire, again indicating that the restructuring process and its changes had positively affected employee attitudes (according to the Likert-scale used).

Thus the null hypothesis relating to this part of the study is supported and the altemative hypothesis rejected.

\section{CONCLUSIONS AND RECOMMENDATIONS}

The results of the study show that the organisation climate and the attitudes of employees of the specific organisation had both been affected by the organisation 
restructuring process, and that the direction of change of the employees' perceptions of these dimensions was positive. These findings support those of Donaldson (1994) that organisation restructuring, as a form of "global" change of the organisation, have definite implications for changes in culture, climate, and employee attitudes and perceptions regarding their jobs and the broader working/organisation environment. The results of the study also support the findings of Zimbardo and Leippe (1991) that organisation restructuring is often tantamount to radical organisation climate or culture changes, with accompanying employee feelings of insecurity, resulting in attitude shifts and changed perceptions of jobs and work.

Conclusions with regard to the dimension of organisation climate are the following:

Identity: Employee identification with the organisation showed a marked improvement after restructuring. More emphasis was placed on pride of belonging to the organisation, and employees were better able to align personal objectives with those of the organisation.

Recognition: This element changed after restructuring, in that employees felt more certain that management would recognise their efforts and achievements. Possible reasons for this could be that the consultants and management responsible for implementing the restructuring interventions, carefully considered the needs and wishes of all stakeholders in the organisation, thus promoting a sense of personal recognition amongst employees.

Responsibility: After the restructuring, employees felt more confident that they were able to use greater initiative, as well as to take more responsibility in their work. Roles and responsibilities were more clearly defined, in tum suggesting more organisational loyalty, greater flexibility and higher achievement, both on an individual level and in group context.

Standards: The organisation restructuring process addressed issues such as work standards and performance. After the restructuring, it seems that greater emphasis was placed on continual improvement of organisational standards, especially in terms of higher work/job standards. Standards are influenced by employees' perceptions of the goals and work standards set by the organisation.

Support: Support refers to the extent to which employees perceive the organisation as one in which they will be able to obtain information freely, as well as whether other members and management are seen to act in a helpful and encouraging manner. After restructuring, employees felt more confident about the support they would receive from management and peers. This would indicate a 
higher level of trust within the organisation, as well as an environment where greater sharing of information takes place.

Structure: The study shows that employees experienced a more effective working environment within the organisation after the restructuring process. Employees had greater clarity about the nature of the organisation and management structures.

Warmth: After the restructuring, employees found that greater emphasis was placed on a friendly and warm organisational atmosphere.

Conflict: After restructuring, employees felt more at ease about conflict and the way it was handled, as fear of reprisal was minimised. There seemed to be a move towards a more open style of conflict management. This may mean that management is not afraid of opposing views amongst employees, and that there is an emphasis on immediate settlement of differences.

Risk: Although the general level of risk-taking remained almost constant after the organisational restructuring, this study indicates a tendency on the part of the company and its employees to take more calculated risks.

Conclusions regarding the impact of the organisational restructuring process on employee attitudes are the following:

- Employees felt that the changes that were implemented in the organisation had far reaching effects.

- Employees were affected directly both personally and professionally by the changes that were implemented.

- The implemented changes were effectively communicated to employees prior to being implemented.

- Employees felt that the changes made to the organisation's structure do not hold a current threat to their job security.

- Employees are convinced that the changes implemented were in fact necessary for the survival of the organisation.

- Employees identified strongly with the organisation after the restructuring process and did not seek alternative employment.

The level of conflict amongst organisation members decreased after the organisational restructuring.

- Employees took a personal interest in the changes that were being implemented.

- Changes are seen to be positive in that they bring about new challenges, as well as opportunities for success to employees.

- Cooperation and team spirit were increased after the restructuring process. 
- Stakeholders within the organisation supported the change process.

With the experiences and results gained from this study, the following recommendations are suggested:

Communication: The quality of communication has a direct influence on the success of a widespread structural intervention. It is therefore of utmost importance that a comprehensive plan be drawn up and made known to all stakeholders prior to the implementation of such a change project. Information about inputs, processes, methodologies and desired outcomes should effectively and timeously be made available to employees. Effective communication also plays a significant role in overcoming resistance to change, as fears can be addressed by management and other agents of change.

Performance management systems: Performance management systems provide employees with opportunities to effectively measure own performance against those that the organisation has set. Clearly defined goals are established by management and communicated to employees. Employees are able to comment and make amendments during these feedback sessions. This also provides an opportunity for improved communication between different levels of the organisation hierarchy, in terms of both top-down and bottom-up communication.

Climate study: It is suggested that the organisation conduct a climate study approximately two years after the restructuring process, in order to re-evaluate the various elements used in this study, as well as to re-align organisation goals and communicate these goals to employees.

Organisational change, a seemingly painful process, can be implemented with success, as illustrated by this study. Certain fundamentals, such as effective communication, should however be upheld. Various successful methodologies are already in existence and utilised by management and other agents of change. These processes should however be adapted to suit the needs of each individual organisation.

\section{REFERENCES}

1 DONALDSON, G. (1994) Corporate Restructuring: Managing the Change Process from Within, Harvard Business School Press, First ed., $658.1612 \mathrm{O} / \mathrm{S}$.

2 HEYMANS, K. (1997) "Culture versus Climate", Unpublished MBA dissertation, University of South Africa, Pretoria. 
3 KOCHAN, T.A. \& USEEM, M. (1992) Transforming Organisations, First Ed, Oxford University Press.

4 LAMBERTON, L.H. \& MINOR, L. (1995) Human Relations: Strategies for Success, First ed., Irwin Mirror Press.

5 LITWIN, G.H. \& STRINGER, R.A. (1968) Motivation and Organisational Climate, First Ed., Division of Research, Graduate School of Business Administration, Harvard University.

6 MILTON, C.M. (1981) Human Behaviour in Organisations: Three Levels of Behaviour, First ed., Prentice Hall, Inc.

7 MORAN, E.T. \& VOLKWEIN, J.F. (1992) "The Cultural Approach to the Formation of Organisational Climate", Human Relations, 45 (1).

8 OTTERMAN, C.I. (1991) "Die Bëlewing van Organisasieklimaat en Stres by Bestuurders van "n Nasionale Diensorganisasie", Unpublished M Com (Human Resource Management) thesis, University of Pretoria, Pretoria.

9 ROBBINS, S.P. (1996) Organisational Behaviour: Concepts, Controversies, Applications, 7 th ed., Prentice Hall International Editions.

10 VELDSMAN, F.H.J. (1995) "Die Invloed van enkele Biografiese Veranderlikes op die Werknemer se Persepsie van Organisasieklimaat en Organisasieverbondenheid", Unpublished M Com (Human Resource Management) thesis. University of Pretoria, Pretoria.

11 ZIMBARDO, P.G. \& LEIPPE, M.R. (1991) The Psychology of Attitude Change and Social Influence, First ed., McGraw-Hill, Inc. 